\title{
A CONQUISTA DO ESPAÇO: AS RELAÇÕES LITERÁRIAS DE CYRO MARTINS COM A LIVRARIA DO GLOBO ENTRE 1933-1945
}

\section{THE CONQUEST OF A POSITION: THE LITERARY RELATIONS BETWEEN CYRO MARTINS AND LIVRARIA DO GLOBO FROM 1933 TO 1945}

\author{
Fábio Varela Nascimento" \\ Luiz Antonio de Assis Brasil ${ }^{* *}$
}

\begin{abstract}
Resumo: Este artigo investiga as relações literárias entre o escritor Cyro Martins (1908-1995) e a Livraria do Globo, de Porto Alegre, no período que vai de 1933 a 1945. A aproximação do autor com a editora, as colaborações na Revista do Globo e a publicação, pela Globo, de Campo fora (1934), Enquanto as águas correm (1939), Mensagem errante (1942) e, principalmente, de Porteira fechada (1944) foram essenciais para que Cyro Martins conquistasse uma posição no sistema literário do Rio Grande do Sul. O trabalho utiliza um conceito de sistema derivado das noções de Antonio Candido $(2010,2013)$ e de Itamar Even-Zohar (2013) e aborda tanto a produção literária de Cyro Martins quanto a sua fortuna crítica.
\end{abstract}

Palavras-chave: Cyro Martins; Livraria do Globo; sistema literário.

Aвstract: This article investigates the literary relations between the writer Cyro Martins (1908-1995) and the Livraria do Globo from Porto Alegre in the period from 1933 to 1945. The author's approach with the publisher, the collaborations in Revista do Globo and the publication, by Globo, from Campo fora (1934), Enquanto as águas correm (1939), Mensagem errante (1942) and, mainly, from Porteira fechada (1944) were essential for Cyro Martins to conquer a position in the literary system of Rio Grande do Sul. The work uses a concept of system derived from the notions of Antonio Candido (2010, 2013) and Itamar Even-Zohar (2013) and addresses both the literary production of Cyro Martins and his critical fortune.

Kerwords: Cyro Martins; Livraria do Globo; literary system.

\footnotetext{
"Doutor em Letras pela PUCRS, professor da rede pública estadual do Rio Grande do Sul. E-mail: fv.nasci@gmail.com. "Escritor, Doutor em Letras pela PUCRS, professor na Escola de Humanidades da PUCRS, bolsista de produtividade do CNPq. E-mail: laab@pucrs.br.
} 


\section{INTRODUÇão}

Cyro Martins (Quaraí, 1908 - Porto Alegre, 1995) foi um médico e psicanalista que, mesmo dedicando apenas o "rabo das horas" (INSTITUTO..., 1984, p. 6) à literatura, escreveu e publicou quase duas dezenas de títulos. Sua produção é tão extensa quanto variada. Estreou em 1934 com Campo fora, livro de contos em que ficava evidente a inspiração regionalista. Pouco tempo depois, voltou-se para as narrativas longas: Sem rumo, de 1937, Porteira fechada, de 1944, e Estrada nova, de 1954, que formaram a Trilogia do gaúcho a pé, eram romances nos quais havia uma preocupação com o destino do trabalhador rural obrigado a deixar o campo e a migrar para os centros urbanos; Enquanto as águas correm, de 1939, e Mensagem errante, de 1942, apresentavam-se como tentativas mais ousadas - a primeira apostava na densidade psicológica do protagonista, um estrangeiro vagando pelo pampa, a segunda, com estrutura mais complexa, tinha toques autobiográficos; em outro momento de sua carreira, Cyro Martins optou pelos romances que contemplavam acontecimentos históricos do Rio Grande do Sul e do Brasil Sombras na correnteza, de 1979, e O professor, de 1988, abordavam a Revolução de 1923, Gaúchos no obelisco, de 1984, tratava dos desdobramentos da Revolução de 1930. Em outras narrativas longas, o escritor tocou nos temas da loucura e do misticismo (O príncipe da vila, 1982), da violência contra a mulher ( $N a$ curva do arco-íris, 1985) e da impunidade dos feminicidas (Um sorriso para o destino, 1991). Ele ainda retomou as histórias curtas em A entrevista, de 1968, Rodeio, de 1976, e A dama do saladeiro, de 1980.

Além das obras ficcionais, Cyro Martins se dedicou a ensaios sobre psicanálise e a textos de crítica literária. Ao primeiro grupo pertencem Do mito à verdade científica, de 1964, A criação artística e a psicanálise, de 1970, O mundo em que vivemos, de 1983, A mulher na sociedade atual, de 1984, e Caminhos, de 1993; fazem parte do segundo grupo Escritores gaúchos, de 1981, e Páginas soltas, de 1994.

Cyro costumava dizer que era uma "testemunha ocular da história" (MARTINS, SLAVUTZKY, 1990, p. 58), pois viveu por boa parte do século XX, acompanhou revoluções e guerras, viu governos ditatoriais e democráticos, presenciou episódios literários e ajudou a introduzir a psicanálise no Rio Grande do Sul. Um sujeito que tinha essa visão sobre si e deixava vestígios de suas experiências em diversas oportunidades não abriria mão de um livro de memórias. A obra apareceu em 1990, com o título Para início de conversa e a parceria do amigo e psicanalista Abrão Slavutzky.

Fora dos limites regionais, esse escritor de currículo tão extenso nem sempre atraiu os holofotes, mas teve seus momentos significativos. Em fevereiro de 1936, na Rumo, revista mensal de poucos números publicados em Porto Alegre, a nota "Sobre um escritor regionalista" reproduzia uma apreciação de Samuel Putnam referente a Campo fora. O escritor, tradutor, jornalista e sociólogo americano falou que os contos eram "coloridos da vida da fronteira brasileira, cuja época e estilo estão de acordo com os tipos que habitam essa região" (SOBRE..., 
1936, p 24). Itens ${ }^{1}$ que compõem a correspondência do Acervo Cyro Martins, preservado no Delfos - Espaço de Documentação e Memória Cultural da Pontifícia Universidade Católica do Rio Grande do Sul, mostram que Porteira fechada ultrapassou fronteiras em 1944 e chegou a nomes como Cyro dos Anjos e Marques Rebelo, que fizeram comentários positivos a respeito do romance. No primeiro número da revista Província de São Pedro (junho de 1945), na seção Transcrições, encontrava-se uma breve análise de Afonso Arinos de Mello Franco sobre Porteira fechada e Fronteira agreste, de Ivan Pedro de Martins. Cyro também foi mencionado em trabalhos sobre história da literatura (História concisa da literatura brasileira, Alfredo Bosi) e sobre o romance de 1930 (Uma história do romance de 30, Luís Bueno). Produtos de uma outra fase ficcional de Cyro Martins, Sombras na correnteza e Gaúchos no obelisco figuraram nas listas de Seymour Menton (La nueva novela historica de la America Latina, 1979-1992) e de Antônio Roberto Esteves (O romance histórico brasileiro contemporâneo [1975-2000]), além de receberem maiores atenções de Marilene Weinhardt (Ficção histórica e regionalismo: estudo sobre romances do Sul).

No Rio Grande do Sul, Cyro Martins alcançou uma posição destacada. A partir da década de 1940, seus livros tiveram uma repercussão mais expressiva, pois intelectuais relevantes na cena cultural gaúcha avaliaram sua produção. Moysés Vellinho, Augusto Meyer, Guilhermino César e Dyonélio Machado foram alguns dos nomes que se debruçaram sobre a obra do escritor quaraiense. Nos anos 1970, a ficção de Cyro - principalmente aquela que compunha a Trilogia do gaúcho a pé - passou a ser alvo de pesquisas acadêmicas, o que ainda se dá, e no seu septuagésimo aniversário, em 5 de agosto de 1978, o “Caderno de Sábado" do jornal Correio do Povo dedicou-lhe uma edição especial. Na década de 1980, uma das mais produtivas da carreira do autor, ele recebeu diversas homenagens: o primeiro fascículo da série Autores gaúchos, do Instituto Estadual do Livro (1984), tratou de Cyro Martins e, em 1986, ele foi escolhido patrono da Feira do Livro de Porto Alegre. Após a morte de Cyro, sua obra e sua figura continuaram em destaque. Os familiares fundaram, em 1997, o Centro de Estudos de Literatura e Psicanálise Cyro Martins (CELPCYRO), instituição que promove eventos e apoia o desenvolvimento de trabalhos relacionados a Cyro. Com o objetivo de disponibilizar a biblioteca, a correspondência, os originais e os documentos pessoais do escritor para pesquisadores, em 2008, o Acervo Cyro Martins foi cedido ao Delfos/PUCRS.

Cyro Martins era reconhecido como membro saliente da cidade das letras gaúcha. É claro que a conquista de seu espaço no sistema literário do Rio Grande do Sul ocorreu com o passar do tempo e, nessa trajetória, o período entre 1933 e 1945 foi fundamental - assim como foram imprescindíveis as relações que Cyro estabeleceu com a Livraria do Globo na mesma época.

A Globo era a principal casa editorial do Sul do país e sua marca estava tão ligada à tradução de literatura estrangeira quanto à publicação de escritores regionais. Cyro era, justamente, um autor de alcance regional, e a Seção Editora da Livraria do Globo, naqueles

${ }^{1}$ Os itens são um telegrama enviado por Cyro dos Anjos em 16 de junho de 1944 e uma carta enviada por Marques Rebelo em 20 de junho de 1944. 
tempos, apresentava-se como sua melhor opção. Atrelando-se à Globo, ele não só veria seus livros impressos, mas também faria parte de um sistema literário dinâmico, pois a Livraria do Globo editava, preparava o lançamento dos novos produtos, divulgava-os e dava mostras de sua recepção. Durante esse processo, o escritor ficava em evidência ao ver seu trabalho nas vitrines das lojas da Livraria do Globo e nas páginas da Revista do Globo ou da Província de São Pedro, periódicos que, de uma maneira ou de outra, faziam ecoar as publicações da casa. Estar inserido na dinâmica da Globo era essencial para conquistar um espaço literário. Cyro conseguiu a inserção em muitas ocasiões e isso foi determinante para que seu nome tivesse lugar na história da literatura do Rio Grande do Sul. Antes de analisar os graus de interação de Cyro Martins com a Livraria do Globo entre 1933 e 1945, faz-se necessário elaborar uma noção de sistema literário e, para isso, é preciso recorrer às ideias de dois teóricos que refletiram sobre o tema: Antonio Candido e Itamar Even-Zohar.

\section{UMA CONSTRUÇÃO DE SISTEMA}

Em trabalhos da década de 1950, o brasileiro indicou o que entendia por sistema e o que o formava. Na conferência "A literatura e a vida social" (1957), posteriormente publicada em Literatura e sociedade, analisando as influências do meio social sobre as obras de arte, Candido (2010, p. 33) citou "os três elementos fundamentais da comunicação artística - autor, obra, público". Esse tripé mostrou-se essencial para a elaboração de Formação da literatura brasileira: momentos decisivos (1959), estudo que investigava os caminhos entre as manifestações literárias do Brasil Colônia até o estabelecimento de um sistema nos tempos do reinado de Dom Pedro II. Antonio Candido abriu a Formação com um capítulo de título sintomático, "Literatura como sistema", e salientou a concepção de literatura como um sistema simbólico no qual se distinguem:

[...] a existência de um conjunto de produtores literários, mais ou menos conscientes de seu papel; um conjunto de receptores, formando os diferentes tipos de público, sem os quais a obra não vive; um mecanismo transmissor, (de modo geral, uma linguagem, traduzida em estilos), que liga uns aos outros (CANDIDO, 2013, p. 25).

O esquema autor, obra e público é significativo para apurar as relações entre alguns elementos do sistema e tem relevância para pesquisas que envolvam a literatura, a história e a sociologia. Porém, para os objetivos aqui pretendidos, mostra-se um tanto lacunar e reduzido, pois não exibe outros elementos importantes para a dinâmica de um sistema tão intrincado quanto o literário. Algumas dessas lacunas talvez possam ser preenchidas com tópicos levantados por Itamar Even-Zohar em “Teoria dos polissistemas” e "Sistema literário”. 
No primeiro deles, publicado originalmente em 1979, Even-Zohar (2013a, p. 3) se posiciona contra o "enfoque estático e sincronístico" - que, segundo ele, surgiu na escola de Genebra - e busca inspiração em Boris Eikhenbaum e Yury Tynyanov, em cujos trabalhos acreditava ser possível encontrar "as raízes do enfoque dinâmico". É precisamente a noção de dinâmica que interessa para o crítico israelense. Para ele, sistema não é um circuito fechado que pode ser analisado de maneira individual, mas um conjunto de estrutura complexa, "algo dinâmico e heterogêneo" (ZOHAR, 2013a, p. 3), aberto às movimentações dos seus aspectos internos e às possibilidades de intersecções com outros sistemas. A complexidade, a multiplicidade e a heterogeneidade estão na base do pensamento de Even-Zohar, por isso a opção pela ideia do polissistema. A palavra remete ao tom de variedade, o que é importante para se ter uma visão ampla da teoria: dentro do polissistema da cultura brasileira, pode haver diversos sistemas relacionados à literatura, à música, às artes plásticas-e, dentro desses sistemas, outros. Nessa série de sistemas, o funcionamento e os eventos de um podem afetar a dinâmica de outro.

Lançado em 1984, "Sistema literário" reforça o sentido que sistema tem dentro da teoria: "o termo supõe um compromisso com o conceito de 'sistema' do funcionalismo (dinâmico), isto é, a rede de relações que podem hipotetizar-se (propor como hipótese) para um conjunto dado de observáveis ('eventos'/'fenômenos')" (EVEN-ZOHAR, 2013b, p. 22). A essa explicação de tom amplo segue-se uma mais específica:

De modo breve, o significado de 'sistema literário' para a teoria dos polissistemas pode ser formulado assim:

A rede de relações hipotetizadas entre uma certa quantidade de atividades chamadas 'literárias', e, consequentemente, essas atividades observadas através dessa rede (EVEN-ZOHAR, 2013b, p. 23).

A partir da formulação, entende-se que um sistema existe devido à rede de relações efetuadas entre os seus fatores. Adaptando o esquema de comunicação e linguagem de Roman Jakobson, Even-Zohar (2013b, p. 27) estabeleceu os "macrofatores implicados no funcionamento do sistema literário": instituição, repertório, produtor, consumidor, mercado e produto.

A instituição "consiste no conjunto de fatores implicados na manutenção da literatura como atividade sociocultural" (EVEN-ZOHAR, 2013b, p. 35), inclui alguns produtores - os críticos e os grupos de escritores -, editoras, periódicos, estabelecimentos educativos, meios de comunicação e outros. Dentro da instituição, existem "lutas pelo domínio" (EVEN-ZOHAR, 2013b, p. 35), pois diferentes grupos tentam ocupar seu centro. Ao entender que a literatura pode se manifestar em vários níveis, Even-Zohar (2013b, p. 38) compreende que "o 'repertório literário' pode ser pensado como um conjunto de repertórios específicos para cada um desses níveis” e que um “'repertório', portanto, pode ser o conhecimento compartilhado necessário tanto para produzir (e entender) um 'texto', como para produzir (e entender) vários outros produtos do sistema literário”. Para Even-Zohar, o papel do produtor não está atrelado apenas 
à produção de textos literários ou críticos, ele pode assumir a faceta de consumidor, associar-se a grupos a fim de integrar uma instituição para legitimar-se ou legitimar e agir para ocupar o centro de uma instituição. Como o produtor, o consumidor "pode se mover em vários níveis como participante das atividades literárias" (EVEN-ZOHAR, 2013b, p. 33). O teórico também entende que há consumidores diretos e indiretos. No primeiro caso, que atinge um número mais restrito de pessoas, existe um interesse deliberado pelas atividades literárias; no segundo, de maior abrangência, os membros de uma comunidade simplesmente consomem "uma quantidade de fragmentos literários, digeridos e transmitidos por variados agentes culturais e integrados no discurso diário" (EVEN-ZOHAR, 2013b, p. 33). No mercado estão os fatores envolvidos no "comércio de produtos literários e na promoção de tipos de consumo" (EVENZOHAR, 2013b, p. 33): livrarias, clubes de leitura, bibliotecas e elementos que proporcionam intercâmbios simbólicos. Quando trata de produto, Even-Zohar (2013b, p. 41) não se restringe a citar somente "textos"; para ele, todo "resultado de uma atividade qualquer, pois, pode ser considerado 'produto', seja qual for sua manifestação ontológica”.

O sistema concebido por Itamar Even-Zohar é complexo e detalhado, mas prescinde de maior objetividade - traço visível nas proposições de Antonio Candido. Diante disso, é possível realizar um exercício teórico no qual as duas interpretações estejam adaptadas, utilizar as ideias relativas à dinamicidade externa e interna, à instituição, ao produtor, ao produto e ao público e direcionar o estudo para Cyro Martins, a Livraria do Globo e o sistema literário do Rio Grande do Sul entre os anos 1933 e 1945.

\section{A busca pelo espaço}

Cyro Martins era um produtor que buscava a inserção no sistema literário desde 1926, quando apresentou ao público dois produtos: "Na estrada" e "Viagem noturna". Os contos saíram nas duas primeiras edições (julho e outubro) de Vibração: revista de literatura e illustração. Fundada pelo "entusiasmo de uma falange de moços estudantes" (GRAEFF; RIBEIRO; SANTOS, 1926, p. 1), a Vibração durou pouco - mesmo estampando anúncios em algumas páginas, o periódico não chegou ao terceiro número. Sem suporte econômico e com possíveis desavenças entre os moços entusiasmados, a Vibração repetia o fadário de tantas outras revistas de vida curta.

Havia exceções que fugiam ao destino da existência efêmera. A Revista do Partenon Literário, por exemplo, durou de 1869 a 1879, tornando-se uma das responsáveis pelo estabelecimento do sistema literário gaúcho. A revista contava com uma rede de assinantes espalhados por diversos municípios, o que, de certo modo, garantia sua circulação. Outra exceção, a Revista do Globo, surgiu cinquenta anos após o encerramento das atividades do periódico da Sociedade do Partenon Literário.

A Revista do Globo apareceu nas bancas entre janeiro de 1929 e fevereiro de 1967, contabilizando um total de 942 fascículos. O quinzenário de cultura e vida social não era apenas 
um veículo de variedades que atingia diferentes faixas de público. Como diz Alice Moreira (1999, p. 109-110), a Revista do Globo "ajudou a construir" a identidade cultural do estado, pois destinava-se "à divulgação de tudo o que ocorresse, digno de registro", no Rio Grande do Sul, no Brasil e no mundo. Na composição de suas páginas, havia textos, fotografias e propagandas, sendo que muitos dos anúncios eram vinculados à Livraria do Globo, a alma mater do periódico.

Desde sua fundação em 1883, a Globo crescia como empresa, contando com seções de tipografia, fotogravura, cartonagem, litografia, impressão e assistência aos clientes da Royal. A casa também editava livros didáticos e literários - esses em pequenas tiragens-, mas entrou com força no mercado livreiro na década de 1920, quando começou a publicar autores regionais e obteve direitos para "a distribuição exclusiva de grandes editoras europeias" (MOREIRA, 1999, p. 109). Isso gerou a necessidade de divulgação dos novos produtos, e a solução encontrada por Mansueto Bernardi, "mentor literário da Livraria do Globo" (MARCON, 1999, p. 124), e José Bertaso, seu diretor, foi a criação da Revista do Globo.

Tal movimentação pode ser representativa, no tocante às influências externas e internas dos sistemas. Após estocar e revender papel durante a Primeira Guerra Mundial, a Globo entrou em um patamar econômico mais elevado, com capacidade para fazer investimentos e diversificar suas ofertas. Para vender seus produtos e ocupar o centro de uma rede literária, a Livraria do Globo tinha de tornar conhecidos os nomes dos seus produtores e os seus títulos por algum canal.

Elisabeth Torresini (1999, p. 57) lembra que, "a partir de 1926 começam a aparecer sistematicamente anúncios das publicações da Globo" no Correio do Povo e "notas relativas à atividade editorial da Livraria do Globo" no Diário de Notícias. Os dois jornais representavam aquilo que Francisco Rüdiger (2003) caracterizou como uma nova tendência na imprensa do Rio Grande do Sul: o afastamento do jornalismo político-partidário e a adoção da visão empresarial. É importante salientar que o cenário político favorecia essa tendência, uma vez que a administração estadual de Getúlio Vargas buscou esfriar as hostilidades entre os partidários de Antônio Augusto Borges de Medeiros e os de Joaquim Francisco de Assis Brasil. Na Livraria do Globo, imperava a visão empresarial e o momento se mostrava propício, como afirma Rüdiger (2003, p. 81):

A revista foi criada no vazio deixado pelo fracasso das publicações anteriores do gênero, devido à falta de sustentação econômica. A capital exigia uma nova revista, as elites viam nela uma necessidade cultural e havia o estímulo do próprio governador Getúlio Vargas.

A confluência de circunstâncias políticas, econômicas e culturais colocou a Livraria do Globo em uma posição de destaque no sistema literário do Rio Grande do Sul. A editora tomava a forma de instituição, pois seu papel era fundamental na manutenção da literatura como atividade sociocultural. A Revista do Globo era peça-chave para essa instituição e as relações 
firmadas no sistema: antecipava e propagandeava produtos, lançava e legitimava produtores, atingia um grande público.

Conforme Alice Moreira (1999), a Revista do Globo publicou textos de 1085 autores. Entre eles estavam Honoré de Balzac, Marcel Proust, Edgar Allan Poe, James Joyce, Aldous Huxley, Rabindranath Tagore, Carlos Drummond de Andrade, Ronald de Carvalho, Humberto de Campos, Augusto Meyer, Erico Verissimo, Mario Quintana, Lila Ripoll. Cyro Martins entrou para o grupo dos escolhidos em maio de 1933, com "Derrotado".

O conto apresenta uma trama simples: o protagonista tenta voltar para casa depois de uma das tantas lutas fratricidas vividas no Rio Grande do Sul, mas se depara com um piquete inimigo e, sem opções, pega sua "adaga fiel” (MARTINS, 1933a, p. 57) para encarar a morte. A narrativa não traz experimentações de linguagem e reproduz uma imagem recorrente na literatura regionalista - a do gaúcho peleador e corajoso. É possível que o público não tenha visto nada de diferente no autor que estreava nas páginas da Revista do Globo, afinal, histórias como aquela foram contadas por João Simões Lopes Neto, Alcides Maya e Darcy Azambuja. Entretanto, para Cyro Martins, o momento era ímpar: pela primeira vez sua produção chegava a um número significativo de leitores. Além disso, com "Derrotado", ele indicava qual era sua filiação literária.

Cyro Martins voltou a aparecer na Revista do Globo em setembro do mesmo ano com "Flete". Confuso, o conto se desenvolvia ao redor de um peão e do seu cavalo - o flete do títuloque salvou a vida do homem quando houve o estouro de uma manada de éguas xucras. A ligação entre o gaúcho e o cavalo era explorada desde os tempos do Partenon Literário e não apontava nenhuma inovação temática. Em "Flete", Cyro reafirmou a filiação a Alcides Maya, pois se aventurou em neologismos e construções frasais duvidosas como: "Solto o animal rebolcou-se rudemente na grama miúda, unimesmando-se com o chão acolhedor" (MARTINS, 1933b, p. 28).

A exposição de Cyro Martins na Revista do Globo em 1933 revela-se sintomática quando relacionada a um fato ocorrido no ano seguinte - a edição, pela Livraria do Globo, de Campo fora. "Derrotado", "Flete" e outros doze contos faziam parte do livro. A aposta em um escritor jovem podia ser feita por causa do momento da Globo. Em 1931, Mansueto Bernardi foi para o Rio de Janeiro ser diretor da Casa da Moeda e suas funções foram herdadas por Henrique Bertaso, filho de José Bertaso, e Erico Verissimo. O primeiro assumiu a chefia da Seção Editora; o segundo, a direção da Revista do Globo. Logo os dois formaram uma parceria decisiva para os rumos da empresa.

Henrique Bertaso achava que a editora "precisava ser reformada, modernizada, dinamizada, livrar-se de seu ranço provinciano" (VERISSIMO, 1972, p. 27). Para que isso acontecesse, o catálogo tinha de ser diversificado e os livros vendidos. Torresini (1999, p. 70) salienta que, entre 1931 e 1933, a Globo lançou “a Coleção Espionagem; a Coleção Verde, romances para senhoras e senhoritas; a Coleção Nobel, com obras de autores célebres da literatura universal contemporânea, e a Coleção Universo, o mais rico filão da editora, cujo principal nome é Karl May”. 
Com essas e outras coleções - a Amarela, de novelas policiais, e a Inquéritos, sobre a Rússia -, a Seção Editora, que também trabalhava com livros técnicos e didáticos, obteve êxito comercial.

Erico Verissimo foi essencial no processo de modernização e dinamização da Globo, pois atuava como diretor da Revista do Globo, tradutor e conselheiro editorial. Ele também publicava seus livros, mas o sucesso literário viria somente no final dos anos 1930. Pela importância de seu papel na revista e na Seção Editora, Verissimo devia receber originais de aspirantes a escritor e indicações de nomes. É provável que isso tenha ocorrido com Cyro Martins. Estudante de medicina em Porto Alegre, frequentava a livraria e sustentava amizades com Augusto Meyer e João Otávio Nogueira Leiria, autores da casa. Portanto, é plausível a hipótese de que a rede de relações de Cyro proporcionou seu ingresso na Globo.

No ano do lançamento de Campo fora, Cyro Martins não estava mais na capital. Com o diploma de médico na mão, fora exercer a profissão em Quaraí. Ele só voltou a morar em Porto Alegre em 1938. Nesse intervalo de tempo, houve o distanciamento da Livraria do Globo e uma tentativa de se projetar para fora do Rio Grande do Sul. Em quatro anos, apenas um dos seus textos apareceu na Revista do Globo - "Conto sem nome", no número de setembro de 1935 que fazia referências ao centenário da Revolução Farroupilha. Cyro integrou a seção intitulada "Os melhores regionalistas do Rio Grande do Sul", que contava ainda com Simões Lopes Neto, Darcy Azambuja, Roque Callage e Vargas Neto. "Conto sem nome” era uma das narrativas de Campo fora e tratava do saudosismo. Pedro Ajala, o protagonista, não sentia saudades só dos tempos em que a campanha gaúcha era diferente, sentia saudades do que ele era quando jovem. Embora abordasse um assunto caro aos escritos regionalistas, Cyro falava de um tema que tocava todos os homens: o correr incontrolável do tempo.

Em 1935 parecia haver dois carimbos ligados a Cyro Martins - o de contista e o de regionalista. Talvez isso estivesse prejudicando seus movimentos no sistema tanto quanto a distância do centro dos acontecimentos. Em "A duração do regionalismo no conto sul-rio-grandense", Gilda Bittencourt (2003, p. 64) afirma que a década de 1930 assinalou "o decréscimo da participação do conto na literatura gaúcha, após dois decênios de uma produção significativa do gênero". O romance tomava a posição privilegiada até então ocupada pelo conto e deslocava o foco das tramas do espaço rural para o urbano - Os ratos, de Dyonélio Machado, e Caminhos cruzados, de Erico Verissimo, publicados em 1935, são exemplos dessa mudança.

Por estar atento a essas modificações ou por querer se aventurar em outro gênero, naquele 1935 Cyro Martins escreveu sua primeira narrativa longa. Sem rumo era a história de Chiru, rapaz sem instrução que abandonou o campo e foi morar nas margens de um município do interior gaúcho, onde sobrevivia de bicos, sofria com o descaso e a violência das autoridades. O livro abordava um problema social, refletia vivências de Cyro como médico de cidade pequena e se desenvolvia sobre a ideia da transição de um momento socioeconômico do Rio Grande do Sul para outro. Quando finalizou o romance, Cyro tentou editá-lo pela Livraria do 
Globo. Ele era identificado por Erico Verissimo (1972, p. 23) e José Otávio Bertaso (1993, s/p.) como um amigo da Globo, mas de nada valeu a amizade na questão Sem rumo.

Em “Notas sobre um autor bissexto”: Cyro Martins na literatura sulina, Mariana Chaguri analisou cartas enviadas pelo quaraiense a Augusto Meyer em 1935 e 1936. Na correspondência de 9 de agosto de 1935, Cyro reclamou do silêncio sobre Campo fora - "É grande a minha satisfação pelo que dizes do Campo fora. De há muito eu ansiava pela manifestação de algum de vocês, pois me entristeceu bastante a boicotagem que a crítica de Porto Alegre fez ao meu livreco" (CHAGURI, 2012, p. 107) ${ }^{2}$. Em 29 de agosto do ano seguinte, Cyro fez um pedido: "Desejaria que o nosso amigo Erico, a quem tenho em boa conta [...] tomasse interesse pelo livro, de modo a ser editado ainda este ano" (CHAGURI, 2012, p. 109). Como os desejos de Cyro não se confirmaram, em 21 de outubro de 1936, ele escreveu novamente para Meyer dizendo que os originais de Sem rumo foram devolvidos "em seco, sem uma palavra, sem uma explicação, sem nem mesmo a delicadeza de uma tapeaçãozinha, para que a cousa não fosse tão violentamente chocante" (CHAGURI, 2012, p. 111).

As cartas recuperadas por Chaguri permitem a elaboração de uma provável sequência de eventos: Cyro mandou uma versão de Sem rumo para Augusto Meyer, diretor da Biblioteca Pública do estado; influente na Globo, Meyer falou sobre o romance para Erico Verissimo, que pediu para ver os originais; Cyro enviou o material para a Livraria do Globo e recebeu uma negativa. Os motivos para a rejeição de Sem rumo não são conhecidos, mas algumas hipóteses podem ser levantadas: Campo fora não vendeu, repercutiu ou trouxe prestígio para o catálogo da editora, a Globo não pretendia fazer nova aposta em um autor regional, o livro não era bem realizado. Essa última ideia não é absurda, pois, como salientou Moysés Vellinho (1960, p. 163) anos depois, Sem rumo era composto por "retalhos, pedaços desencontrados, frações dispersas de cenários e figuras".

Rejeitado pela instituição mais poderosa do sistema literário do Rio Grande do Sul, Cyro Martins publicou Sem rumo pela editora Ariel, do Rio de Janeiro. Em carta escrita para João Otávio Nogueira Leiria no dia 4 de janeiro de 1937, Cyro (1937, p. 1) avisou: "Como talvez saibas, estou de viagem este mês para o Rio, onde permanecerei de 6 a 8 meses, fazendo um curso de neurologia. [...] Sem rumo será editado no Rio. Penso chegar a tempo de revisá-lo”. Cyro entrou em contato com Gastão Cruls e Agripino Grieco através de Mânlio Giudice, um amigo gaúcho que fora residir na capital federal após a Revolução de 1930. Acionada em outros pagos, a rede de relações do autor novamente rendeu frutos. A editora já publicara Jorge Amado, José Lins do Rego e Graciliano Ramos, porém, em 1937, estava longe do seu auge porque a José Olympio chegou ao Rio de Janeiro em 1934 e dominou o mercado. Os maus dias da Ariel ficaram refletidos em Sem rumo. A edição era descuidada, com falhas que iam da acentuação das palavras à numeração dos capítulos. Como Campo fora, Sem rumo não repercutiu no Rio Grande do Sul, e Cyro foi relegado à periferia do sistema.

$\overline{{ }^{2} O \text { conteúdo }}$ das cartas foi reproduzido do artigo de Chaguri (2012), não da fonte original. 
Depois de sua temporada carioca, Cyro voltou ao Rio Grande do Sul. Em 1938 ele foi aprovado no concurso para Alienista Assistente do Hospital Psiquiátrico São Pedro e se estabeleceu em Porto Alegre. O retorno era uma oportunidade para que Cyro se reaproximasse da Globo e tentasse ocupar uma posição de destaque na cena literária. Não há pistas de como isso se deu e não se encontra nenhuma publicação da Revista do Globo antecipando o fato, mas, em 1939, um novo livro de Cyro Martins chegou às bancas com o selo da Livraria do Globo. Escrito entre 1937 e 1938, Enquanto as águas correm mostrava um autor mais consciente do seu ofício. O texto tinha uma fluidez maior do que a vista em Sem rumo, e Isidro, o protagonista, era uma figura complexa, preocupada com questões existenciais.

O lançamento de Enquanto as águas correm recebeu atenção reduzida da crítica. Uma das raras análises do romance saiu em setembro de 1939, no Jornal do Estado, e era assinada por Mário Álvarez. Amigo de Cyro, Mário exaltou os aspectos psicológicos de Isidro e tentou resgatar Sem rumo, obra que em sua opinião "não teve no Rio Grande, ao que nos parece, a repercussão merecida” (ÁLVAREZ, 1990, p. 11).

Enquanto as águas correm era um dos sinais de que Cyro Martins voltava à dinâmica literária do Rio Grande do Sul. Os outros apareceram no Correio do Povo. Em $1^{\circ}$ de agosto de 1939, considerado um "nome de projeção" (LITERATURA..., 1939, p. 7) no meio literário gaúcho, ele respondeu à enquete "Literatura dá para viver?" ao lado de Erico Verissimo, Viana Moog, Reynaldo Moura e outros. No ano seguinte, em 31 de outubro, Cyro publicou "Tradições e símbolos", texto no qual elogiava uma conferência proferida pelo escritor e crítico Manoelito de Ornellas. Uma notícia de 15 de novembro dizia que Cyro compareceu a um almoço em homenagem aos intelectuais gaúchos junto com Darcy Azambuja, Moysés Vellinho, Dyonélio Machado e outras dezenas de escritores e jornalistas.

Cyro Martins já integrava o sistema e seus próximos livros fariam com que ele alcançasse uma posição de destaque. Mensagem errante foi publicado pela Livraria do Globo em dezembro de 1942, mas o nome de Cyro e partes do livro já apareciam na Revista do Globo desde o início de 1941. No número de 25 de janeiro, um dos capítulos do romance saiu caracterizado como conto e com o título "Revelação". Na história, o estudante de medicina Carlos se depara com o cadáver de um conhecido no necrotério. O encontro faz com que o rapaz reflita sobre a vida e saia do local "enriquecido na capacidade de sentir" (MARTINS, 1941a, p. 55). O mesmo Carlos voltou à Revista do Globo em 17 de maio, protagonizando "Cena de pensão", outro capítulo de Mensagem errante divulgado como conto e ilustrado por Vitorio Gheno. Dessa vez, o jovem divide a narrativa com dona Margarida, uma companheira de pensão que, "com exagero de adolescente" (MARTINS, 1941b, p. 50), espera a visita do pretendente engambelador. Em 29 de junho de 1942, uma nova narrativa de Cyro saiu na revista - "Você deve desistir, Romualdo". A trama sobre um alcoolista não tinha relação com Mensagem errante, porém, no meio do texto, havia um currículo do autor e a indicação de que seu próximo romance sairia ainda naquele ano. 
Mensagem errante era um passo ousado de Cyro Martins. O romance apresentava um tom autobiográfico, pois acompanhava diversos momentos da existência de Carlos: a infância na campanha, os estudos em um internato católico, as pensões baratas de Porto Alegre, a Faculdade de Medicina, o exercício da profissão em uma cidade pequena. Os leitores informados sobre a biografia de Cyro podem reconhecer com facilidade as semelhanças entre a vida do autor e a do protagonista. Mensagem errante também possuía uma estrutura complexa e um texto mais trabalhado do que aqueles vistos em Sem rumo e Enquanto as águas correm.

Em 1941, a relação entre Cyro Martins e a Livraria do Globo entrou em outro nível. Além de "Revelação" e "Cena de pensão", saiu na revista de 26 de julho a crítica de um livro publicado pela casa - Céu vazio. Na breve análise "Céu vazio": a tristeza, a solidão e o senso de humor na poesia de Lila Ripoll, Cyro exaltava as qualidades dos poemas da amiga e conterrânea. A Revista do Globo estava sob a direção de Justino Martins desde 1939, pois Erico Verissimo passara a se dedicar à Seção Editora. Cyro e Justino compartilhavam o mesmo sobrenome, mas não tinham parentesco. O que ambos poderiam ter era uma proximidade maior - o que não havia com Erico.

Coincidentemente ou não, em 13 de novembro de 1943, pouco depois de Erico se afastar das funções na Globo para passar dois anos nos Estados Unidos, uma nova colaboração de Cyro apareceu na Revista do Globo. Caracterizado como conto, "Gaúcho a pé" trazia Fagundes, sujeito depressivo e atormentado pelos atos violentos que cometera no passado. "Gaúcho a pé" era um capítulo de Porteira fechada, que seria publicado pela Livraria do Globo em 1944. Porém, antes do lançamento do romance, uma reportagem da Revista do Globo de 25 de março de 1945 sobre a marginalização dos gaúchos nas cidades como Quaraí ajudou a divulgar o livro. "Será este o nosso estado?" ocupava nove páginas $(24-31,57)$ e contava com textos de Cyro - "História do gaúcho marginal" - e Justino Martins - "Crônica de uma cidade marginal" e "Fronteira alegre" - e fotografias de Ed Keffel. A propaganda deu resultado, pois em 6 de maio, na seção "Escritores e Livros" da Revista do Globo, Carlos Regius (1944, p. 16) trouxe a notícia de que Porteira fechada era o segundo livro mais vendido pela Livraria do Globo da Rua da Praia e, exibindo uma fotografia da vitrine da loja montada especialmente para o romance, afirmou que Cyro era "um dos mais destacados escritores do Rio Grande".

\section{CoNSIDERAÇõES FINAIS}

Porteira fechada foi um grande acerto literário de Cyro. A temática do gaúcho a pé e o drama de João Guedes, protagonista que vê sua família se desintegrar e sua vida afundar depois da saída do campo, chamaram a atenção do público e colocaram a figura do produtor Cyro Martins em destaque na Livraria do Globo e no sistema literário regional. Em junho de 1945, quando saiu o primeiro número da Província de São Pedro, nova revista da casa, a produção do 
escritor foi legitimada. Três ${ }^{3}$ artigos citaram a obra de Cyro, sendo que o mais significativo deles, "Paz nos campos...", foi assinado por Moysés Vellinho. Além de ser fundador e diretor do periódico, Vellinho era um dos críticos mais conceituados do estado e sua aprovação era essencial. Ele ressaltou o potente sentido social de Porteira fechada, destacou o tom sombrio da narrativa - "O romance é amargo e opressivo" (VELLINHO, 1945, p. 150) - e afirmou que Cyro ofereceu "um pedaço eloquente do áspero deserto de cultura humana laboriosamente criado pela imprevidência e pelas omissões imemoriais da nossa política social e econômica" (VELLINHO, 1945, p. 149).

A repercussão de Porteira fechada era significativa: Cyro Martins tinha conquistado seu espaço na literatura do Rio Grande do Sul. Ao longo de sua carreira como escritor, ele se movimentaria pelo sistema ocupando o centro ou ficando perto da margem, mas não deixaria de ser um nome relevante e reconhecido.

\section{REFERÊNCIAS}

ALVAREZ, M. Enquanto as águas correm. In: MARTINS, Cyro. Enquanto as águas correm. Porto Alegre: Movimento, 1990, p. 11.

BERTASO, J. O. A Globo da Rua da Praia. São Paulo: Globo, 1993.

BITTENCOURT, G. N. S. A duração do regionalismo no conto sul-rio-grandense. Signo, Santa Cruz do Sul, v. 28, n. 45, p. 59-70, 2003.

CANDIDO, A. Formação da literatura brasileira: momentos decisivos. Rio de Janeiro: Ouro sobre Azul, 2013.

CANDIDO, A. A literatura e vida social. Literatura e sociedade. Rio de Janeiro: Ouro sobre Azul, 2010, p. 27-49.

CHAGURI, M. M. Notas sobre um escritor bissexto. Literatura e Autoritarismo, Santa Maria, n. 20, p. 103-120, maio de 2012. Disponível em: http://w3.ufsm.br/literaturaeautoritarismo/ revista/dossie07/RevLitAut_art04.pdf Acesso em: 25 mar. 2021.

EVEN-ZOHAR, I. Sistema literário. Tradução: Luis Fernando Marozo; Yana Karlla Cunha. Translatio, Porto Alegre, n. 5, p. 22-45, 2013b. Disponível em: https://seer.ufrgs.br/translatio/ article/view/42900/27135 Acesso em: 25 mar. 2021.

EVEN-ZOHAR, I. Teoria dos polissistemas. Tradução: Luis Fernando Marozo; Yana Karlla Cunha. Translatio, Porto Alegre, n. 5, p. 1-21, 2013a. Disponível em: http://seer.ufrgs.br/index. php/translatio/article/view/42899/27134 Acesso em 25 mar. 2021.

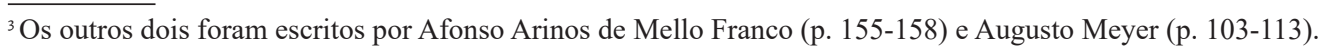


GRAEFF, V.; RIBEIRO, A.; SANTOS, C. Editorial. Vibração: revista de literatura e illustração, Porto Alegre, n. 1, p. 1, julho 1926.

INSITUTO Estadual do Livro. Autores gaúchos - Cyro Martins. Porto Alegre: IEL, 1984. LITERATURA DÁ PARA VIVER? Correio do Povo, Porto Alegre, p. 7, 1 ago.1939.

MARCON, I. Mansueto Bernardi. In: ASSIS BRASIL, L. A.; MOREIRA, M. E.; ZILBERMAN, R. (Org.). Pequeno dicionário da literatura do Rio Grande do Sul. Porto Alegre: Novo Século, 1999, p. 124-125.

MARTINS, C. Cena de pensão. Revista do Globo, Porto Alegre, n. 295, p. 50-52, 17 maio 1941 b. MARTINS, C. [Correspondência]. Destinatário: João Otávio Nogueira Leiria. Quaraí, 4 jan. 1937. (Acervo João Otávio Nogueira Leiria - Delfos/PUCRS)

MARTINS, C. Revelação. Revista do Globo, Porto Alegre, n. 288, p. 22-23,54-55, 25 jan. $1941 a$.

MARTINS, C. Derrotado. Revista do Globo, Porto Alegre, n. 110, p. 14, 57, 3 maio 1933 a.

MARTINS, C. Flete. Revista do Globo, Porto Alegre, n. 119, p. 28, 6 set.1933b.

MOREIRA, A. Livraria e Revista do Globo. In: ASSIS BRASIL, L. A.; MOREIRA, M. E.; ZILBERMAN, R. (Org.). Pequeno dicionário da literatura do Rio Grande do Sul. Porto Alegre: Novo Século, 1999, p. 109-110.

REGIUS, C. Escritores e livros. Revista do Globo, Porto Alegre, n. 362, p. 16, 06 maio 1944.

RÜDIGER, F. R. Tendências do jornalismo no Rio Grande do Sul. Porto Alegre: Editora da UFRGS, 2003.

SOBRE um escritor regionalista. Rumo: revista mensal, Porto Alegre, p. 24, fevereiro de 1936.

TORRESINI, E. R. Editora Globo: uma aventura editorial nos anos 30 e 40. São Paulo: EDUSP, 1999.

VELLINHO, M. Itinerário de um romancista. Letras da província. Porto Alegre: Globo, 1960, p. 159-174.

VEllinho, M. Paz nos campos... Província de São Pedro. Porto Alegre, v. 1, n. 1, p. 147-150, jun. 1945.

VERISSIMO, E. Um certo Henrique Bertaso. Porto Alegre: Globo, 1972.

Recebido para publicação em: 18 jun. 2021. Aceito para publicação em: 18 jul. 2021. 